\title{
State-of-the-Art Update of Pancreatic Cysts
}

\author{
Andrew Canakis ${ }^{1} \cdot$ Linda S. Lee $^{2}$
}

Accepted: 12 May 2021 / Published online: 12 August 2021

(c) The Author(s) 2021

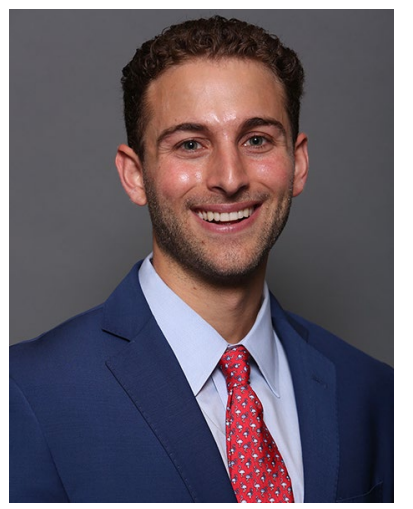

Andrew Canakis

Keywords Pancreatic cyst · Pancreatic cancer - Endoscopic ultrasound · Endoscopic ultrasound fine needle aspiration · Intraductal papillary mucinous neoplasm · Serous cystadenoma · Mucinous cystic neoplasm · DNA markers · Biopsy · Ablation · Guideline $\cdot$ Confocal laser endomicroscopy

$\begin{array}{ll}\text { Abbreviations } \\ \text { PCLs } & \text { Pancreatic cystic lesions } \\ \text { MRI } & \text { Magnetic resonance imaging } \\ \text { SCA } & \text { Serous cystadenoma } \\ \text { MCN } & \text { Mucinous cystic neoplasm } \\ \text { HGD } & \text { High-grade dysplasia } \\ \text { IPMN } & \text { Intraductal papillary mucinous neoplasm } \\ \text { MD } & \text { Main duct } \\ \text { BD } & \text { Branch duct } \\ \text { MRCP } & \text { Magnetic resonance } \\ & \text { cholangiopancreatography } \\ \text { CT } & \text { Computed tomography } \\ \text { PET } & \text { Positron emission tomography } \\ \text { EUS } & \text { Endoscopic ultrasound }\end{array}$

Linda S. Lee

llee@bwh.harvard.edu

1 Division of Gastroenterology and Hepatology, University of Maryland School of Medicine, Baltimore, MD, USA

2 Division of Gastroenterology Hepatology and Endoscopy, Brigham and Women's Hospital, Harvard Medical School, 75 Francis St, Boston, MA 02115, USA

$\begin{array}{ll}\text { CH } & \begin{array}{l}\text { Contrast-enhanced harmonic } \\ \text { EUS-FNA }\end{array} \\ \text { Endoscopic ultrasound-guided fine needle } \\ \text { aspiration } \\ \text { CEA } & \begin{array}{l}\text { Low-grade dysplasia } \\ \text { Carcinoembryonic antigen }\end{array} \\ \text { AGA } & \begin{array}{l}\text { American Gastroenterological } \\ \text { Association }\end{array} \\ \text { EUS-TTNFB } & \begin{array}{l}\text { EUS-guided through-the-needle forceps } \\ \text { biopsy }\end{array} \\ \text { nCLE } & \text { Needle confocal laser endomicroscopy } \\ \text { QoL } & \text { Quality of life }\end{array}$

\section{Introduction}

Pancreatic cystic lesions (PCLs) represent a heterogenous group of lesions with varying degrees of malignant potential and a wide clinicopathologic spectrum that mandates careful diagnostic and therapeutic consideration. Numerous guidelines have been developed to assist in the management of these lesions (Table 1) [1-7]. However, the diagnosis and management of PCLs remain problematic due to the variable biological behavior of these lesions, cost of surveillance, 
Table 1 Summary of current pancreatic cyst guidelines

\begin{tabular}{|c|c|c|c|c|c|}
\hline & AGA (2015) & Fukuoka (2017) & ACG (2018) & European (2018) & ACR (2017) \\
\hline Cyst Type & Incidental cysts & Mucinous cysts & All pancreatic cysts* & $\begin{array}{l}\text { All common pancre- } \\
\text { atic cysts }\end{array}$ & Incidental cysts \\
\hline Imaging type & MRI pancreas & $\begin{array}{l}\text { Pancreatic protocol } \\
\text { CT or MRI pancreas }\end{array}$ & MRI pancreas & MRI pancreas & $\begin{array}{l}\text { Pancreatic protocol CT } \\
\text { or contrast MRI }\end{array}$ \\
\hline Indications for EUS & $\begin{array}{l}\text { At least two high-risk } \\
\text { features** }\end{array}$ & $\begin{array}{l}\text { At least one worri- } \\
\text { some feature }{ }^{* * *}\end{array}$ & $\begin{array}{l}\text { At least one worri- } \\
\text { some feature } * * *\end{array}$ & $\begin{array}{l}\text { At least one clinical } \\
\text { or radiologic con- } \\
\text { cerning features } * * *\end{array}$ & $\begin{array}{l}\text { Cyst growth } \\
\text { (<5 mm, 100\% growth; } \\
5-15 \mathrm{~mm}, 50 \% \\
\text { growth; }>15 \mathrm{~mm} \text {, } \\
20 \% \text { growth), periph- } \\
\text { eral calcification if } \\
\text { cyst }>2.5 \mathrm{~cm} \text {, or } * * * *\end{array}$ \\
\hline $\begin{array}{l}\text { Indications to refer } \\
\text { for consideration of } \\
\text { surgery }\end{array}$ & $\begin{array}{l}\text { Dilated main pan- } \\
\text { creatic duct }+ \text { solid } \\
\text { component and/or } \\
\text { positive cytology }\end{array}$ & $\begin{array}{l}\text { At least one high-risk } \\
\text { stigmatal }^{\wedge}\end{array}$ & $\begin{array}{l}\text { At least one concern- } \\
\text { ing symptom or } \\
\text { sign, imaging, } \\
\text { cytology } ¥\end{array}$ & $\begin{array}{l}\text { At least on high-risk } \\
\text { stigmata, symp- } \\
\text { tomatic SCA, } \\
\text { cystic neuroendo- } \\
\text { crine }>20 \mathrm{~mm} \text {, or } \\
\text { solid pseudopapil- } \\
\text { lary neoplasm }\end{array}$ & - \\
\hline
\end{tabular}

*Except patients with strong family history of pancreatic cancer or genetic mutations predisposing to pancreatic cancer

**AGA high-risk features: cyst diameter $\geq 3 \mathrm{~cm}$, solid component, dilated main pancreatic duct

***Worrisome features: pancreatitis, cyst $\geq 3 \mathrm{~cm}$ ( $\geq 4 \mathrm{~cm}$ European), enhancing mural nodule $<5 \mathrm{~mm}$ (any size nodule for ACG), thickened cyst wall, main pancreatic duct 5-9 mm, abrupt change in pancreatic duct caliber with distal atrophy, lymphadenopathy, increased serum CA 19-9, cyst growth rate $\geq 5 \mathrm{~mm} / 2$ years ( $\geq 3 \mathrm{~mm} /$ year for ACG, $\geq 5 \mathrm{~mm} /$ year for European)

**** Nodule, thickened wall, main pancreatic duct $\geq 7 \mathrm{~mm}$, extrahepatic biliary obstruction/ jaundice

^ High-risk stigmata: obstructive jaundice with cyst in head of pancreas, enhancing nodule $\geq 5 \mathrm{~mm}$, main pancreatic duct $\geq 10 \mathrm{~mm}$, suspicious/ positive cytology, $\mathrm{MCN}$ ( $\geq 4 \mathrm{~cm}$ European)

$¥$ Obstructive jaundice due to cyst, acute pancreatitis, elevated serum CA 19-9, nodule of solid component, main pancreatic duct $>5$ mm, focal dilation of main pancreatic duct concerning for MD-IPMN or obstructing lesion, $\geq 3 \mathrm{~cm}$ IPMN or MCN, HGD or cancer on cytology, solid pseudopapillary neoplasm

morbidity of surgical resection, lack of reliable diagnostics, and need for improved guidelines. Thus, advances in pancreatic cyst diagnostics and therapeutics with endoscopic ablation techniques require further study. Our review aims to shed light on these advances while highlighting the management strategies for PCLs.

With the advent of higher resolution cross-sectional imaging techniques, incidental PCLs have been increasingly discovered. The prevalence in the asymptomatic adult population ranges from 2.4 to $24.3 \%$ [6, 8, 9]. Different imaging modalities have reported variable detection rates ranging from $0.2 \%$ on ultrasound to over $20 \%$ with MRI [10]. De Jong et al. examined 2803 abdominal magnetic resonance imaging (MRI) performed for preventive screening in asymptomatic people in Europe that uncovered 66 (or 2.4\%) PCLs, which increased in frequency with age [8]. Individuals younger than 40 years of age, 70 to 79 years of age, and older than 80 years of age had prevalence rates of $0.5 \%, 11 \%$, and $37 \%$, respectively $[8,9]$. Similar findings were seen in an autopsy series by Kimura et al. [11]. While pancreatic cysts are increasingly being discovered, pancreatic cancer-related mortality has not improved. Hence, managing these PCLs has gained considerable attention as clinicians focus on stratifying the malignant potential of these cysts to prevent the mortality associated with progression to pancreatic cancer.

\section{Common Types of Pancreatic Cysts}

These PCLs may be broadly categorized as mucin producing or nonmucinous lesions. Serous cystadenomas (SCA) are one of the most common nonmucinous cysts that are considered benign neoplasms which occur more commonly in women between the fifth and seventh decades of life along the body-tail region of the pancreas (Fig. 1) [12]. Reassuringly, a large retrospective multinational study of 2622 patients found only three serous cystadenocarcinomas in the entire cohort [13]. Unless a patient is symptomatic or the lesion is large, SCAs should be managed conservatively. If confident the lesion is a SCA, no further imaging surveillance is necessary by most guidelines.

On other end of the spectrum, mucin producing lesions, such as mucinous cystic neoplasms (MCNs) and intraductal papillary mucinous neoplasms (IPMNs), have malignant potential [6]. MCNs are seen mostly in middle aged women 


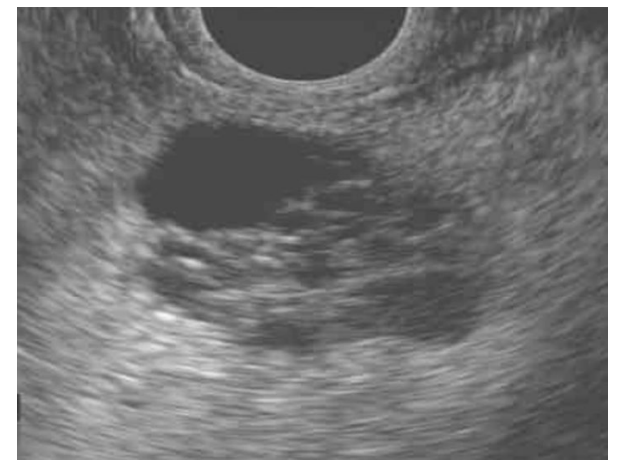

Fig. 1 EUS image of lobular, multiseptated serous cystadenoma

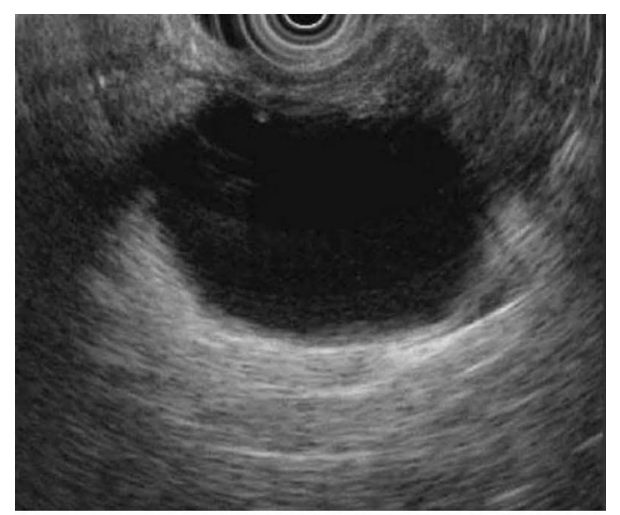

Fig. 2 EUS image of unilocular mucinous cystic neoplasm

as unilocular lesions in the tail of the pancreas without pancreatic duct communication (Fig. 2), and typically surgical resection is recommended [6, 14]. In a study of 90 surgically resected MCNs, high-grade dysplasia (HGD) and pancreatic cancer were seen in $5.5 \%$ and $4.4 \%$, respectively [15]. MCNs carry a 10-39\% risk of malignancy [16] although less than $0.4 \%$ of cysts less than $3 \mathrm{~cm}$ in size without a nodule contain HGD or invasive cancer $[17,18]$. Therefore, the European Study Group refined surgical resection criteria for MCN to those with size at least $4 \mathrm{~cm}$, nodule, and/or symptoms [3]. Surveillance is not necessary following surgical resection of MCN unless pathology shows malignancy as these patients have a nearly $25 \%$ risk of recurrence (Table 2 ) $[1,6]$. The American College of Gastroenterology (ACG) guideline suggests stopping surveillance after 5 years while the other guidelines do not explicitly recommend stopping surveillance.

Intraductal papillary mucinous neoplasms (IPMN) have an equal gender distribution and often occur in the head of the pancreas as solitary or multifocal lesions [16]. IPMNs are radiologically categorized based on their site of involvement within the pancreatic duct: main duct (MD), branch duct (BD), or a combination of both known as mixed (Figs. 3, 4). Malignant potential varies across these different types of IPMNs. MD-IPMNs carry a high risk of malignant transformation of 40 to $90 \%$ with 38 to $68 \%$ shown to harbor HGD or cancer at the time of resection $[6,10]$. Mixed-type IPMNs are thought to have similarly high rates of malignancy (19-68\%) although a subtype with only microscopic involvement of the main duct may have favorable rates of malignancy and survival compared with more extensive involvement of the main duct [19]. These high rates of malignancy lead to recommendations for surgical resection of MD-IPMN and mixed-type IPMNs. On the other hand, BD-IPMNs carry a far lower risk (6 to $46 \%$ ) of malignancy at time of resection with a $22 \%$ risk of malignant transformation $[1,12]$. Therefore, surgical resection is only recommended in patients with at least one worrisome or high-risk feature. It is important to recognize that not all risk factors carry the same likelihood of malignancy. Five-year survival was $96 \%$ for IPMN patients with worrisome features (size $>3 \mathrm{~cm}$, main pancreatic duct 5-9 $\mathrm{mm}$, non-enhancing

Table 2 Surveillance Recommendations Following Surgical Resection

\begin{tabular}{|c|c|c|c|c|}
\hline Pathology & AGA (2015) & Fukuoka (2017) & ACG (2018) & European (2018) \\
\hline Invasive cancer or dysplasia & MRI biennially & - & - & - \\
\hline No HGD or cancer & No MRI surveillance & - & - & - \\
\hline $\begin{array}{l}\text { Invasive cancer in IPMN or } \\
\text { MCN }\end{array}$ & - & $\begin{array}{l}\text { Pancreatic cancer surveil- } \\
\text { lance }\end{array}$ & $\begin{array}{l}\text { Pancreatic cancer surveil- } \\
\text { lance (stop after } 5 \text { years for } \\
\mathrm{MCN} \text { ) }\end{array}$ & $\begin{array}{l}\text { Pancreatic cancer surveil- } \\
\text { lance }\end{array}$ \\
\hline $\begin{array}{l}\text { HGD or non-intestinal type } \\
\text { IPMN }\end{array}$ & - & Q6m & Q6m & $\begin{array}{l}\text { Q6m } \times 2 \text { years, then annual } \\
\text { MRI }\end{array}$ \\
\hline Other IPMN & - & Q6-12 m & $\begin{array}{l}\text { Q24m; if IPMN in remnant } \\
\text { pancreas, follow non- } \\
\text { resected IPMN surveil- } \\
\text { lance }\end{array}$ & $\begin{array}{l}\text { Follow non-resected IPMN } \\
\text { surveillance }\end{array}$ \\
\hline $\begin{array}{l}\text { Non-invasive MCN, serous } \\
\text { cystadenoma }\end{array}$ & - & No MRI surveillance & No MRI surveillance & - \\
\hline
\end{tabular}




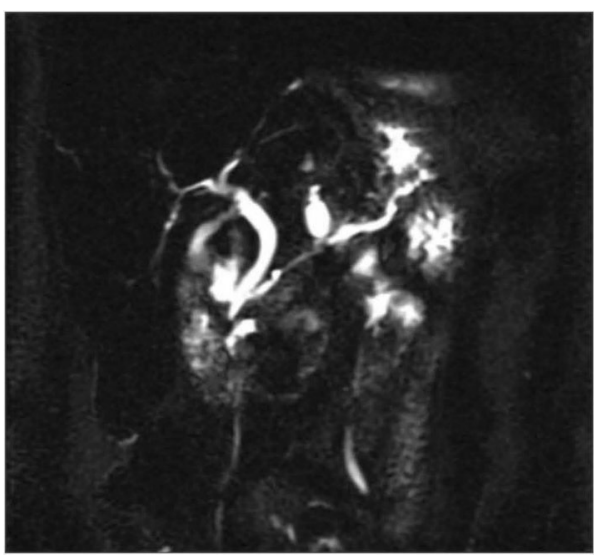

Fig. 3 Mixed type IPMN

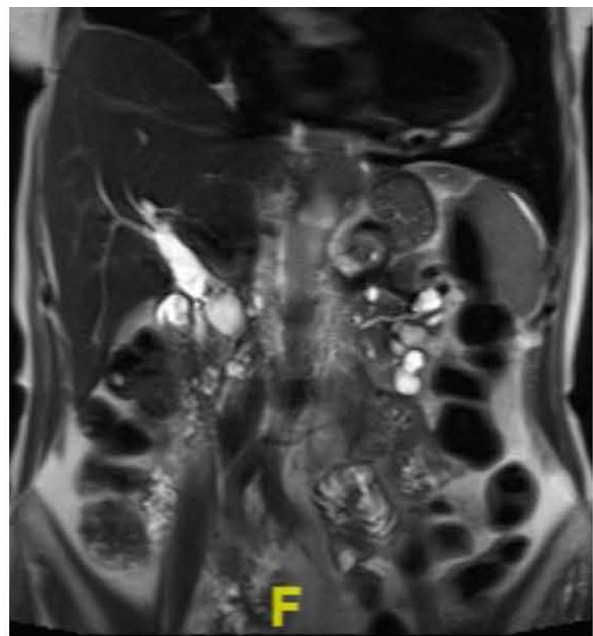

Fig. 4 Branch duct IPMN with nondilated main pancreatic duct and cysts scattered throughout pancreas

nodules, cytology with atypical cells, pancreatitis) compared with $60 \%$ survival for patients with high-risk features (enhancing nodule, main pancreatic duct $\geq 1 \mathrm{~cm}$, cytology with HGD or cancer, jaundice) [20]. Various guidelines recognize different malignant implications of various features by discussing absolute and relative indications for surgery. The absolute indications for resection by the Fukuoka guideline are main duct dilation $\geq 10 \mathrm{~mm}$, jaundice, enhancing nodule $\geq 5 \mathrm{~mm}$, cytology suspicious or positive for malignancy. The European guideline also includes presence of a solid mass and cytology with HGD or malignancy as absolute indications for surgery [3]. Diabetes may be associated with increased risk of main duct involvement, HGD, and invasive cancer [21].

There remains a lifelong risk from IPMNs [2] as even after resection there is a 0 to $65 \%$ risk of recurrence depending on the grade of dysplasia of the resected IPMN [6, 22].
Recurrence includes development of new IPMNs in the remnant pancreas, progression of previously present IPMNs, or occurrence of pancreatic cancer in the remnant pancreas unrelated to an IPMN. Therefore, postoperative surveillance is critical (Table 2).

\section{Diagnostic Work-Up}

\section{Imaging}

Due to variable malignant progression, it is important to characterize these PCLs with high-quality imaging studies to assess for clues of HGD and invasive carcinoma and to determine the type of cyst the patient has in order to guide management. MRI and magnetic resonance cholangiopancreatography (MRCP) are typically preferred over computed tomography (CT) due to lack of radiation and its superior ability to diagnose IPMNs and identify high-risk features. A systematic review of nineteen studies (1,060 subjects) found that $\mathrm{CT}$ and MRI differentiated benign and malignant cysts at similarly fair rates (sensitivity for CT 58\% to $69 \%$ versus $65 \%$ to $77 \%$ for MRI; specificity for CT $64 \%$ to $83 \%$ versus $58 \%$ to $89 \%$ for MRI) [23]. However, MRI was superior for detecting IPMNs (97\% vs $81 \%$ sensitivity) [23] as well as for detecting pancreatic ductal connections, duct involvement, mural nodules, internal septations, and small cysts [3, 4, 24]. The use of gadolinium-enhanced MRI with MRCP can characterize mucinous features, such as ductal communication, with $91 \%$ and $100 \%$ sensitivity and specificity, respectively [25]. It is important to highlight several limitations with gadolinium: (1) additional costs, (2) longer times in the scanner which may increase patient anxiety, (3) risk of nephrogenic systemic fibrosis, and 4) the unclear significance of gadolinium deposition in the brain [26]. One MRI surveillance study found that the use of gadolinium did not change clinical management decision in 56 PCLs [27]. Therefore, it may be reasonable to perform surveillance MRI without gadolinium unless concerning features are identified. Secretin-stimulated MRCP may improve anatomical visualization of ductal communication, and Rastegar et al. demonstrated it was identified only by secretin-enhanced studies in $4.7 \%$ of patients $(p=0.04)$ [28]. Therefore, secretin-stimulated MRCP may be useful in rare situations to confirm diagnosis of BD-IPMN.

The ability for positron emission tomography (PET) to characterize the metabolic activity and stratify the subtype of IPMNs has proved to be a useful tool in differentiating benign versus malignant lesions with a sensitivity, specificity and accuracy of $80 \%, 95 \%$, and $87 \%$, respectively [29]. Srinivasan et al. conducted a systemic review and found that PET was superior to the Fukuoka guideline in detecting malignant IPMNs [30]. PET alone is inferior to CT, though 
the combination of both modalities has been shown to distinguish benign from malignant cysts better than $\mathrm{CT}$ imaging alone [23]. A prospective study of 31 cysts ( 25 benign, 6 malignant) showed that PET/CT was more accurate (94\%) than CT (77\%) and MRI (87\%) imaging for differentiating malignant from benign cysts [31]. However, there is not enough evidence to recommend PET/CT as a go-to imaging technique [6]. All of these imaging studies are subject to misdiagnosis even when reviewer certainty is high [32].

Since MRI, MRCP, and CT have less than 50\% accuracy for diagnosing the specific type of cyst in a patient, endoscopic ultrasound (EUS) has emerged as a secondary diagnostic modality to evaluate cysts further [6]. EUS imaging provides visualization of wall thickness, borders, septations, masses, mural nodules, papillary projections, and communication with the main pancreatic duct. However, like CT and MRI, EUS imaging alone is limited in its ability to diagnose lesions with Brugge et al. reporting only $51 \%$ diagnostic accuracy for differentiating mucinous from nonmucinous cyts [33]. EUS imaging may be helpful in identifying nodules, which are important prognostic features. Topazian's group described nodules as hypoechoic with well-defined hyperechoic rim while mucus appeared isoechoic or hyperechoic compared to the adjacent parenchyma with an illdefined border [34]. Contrast-enhanced harmonic $(\mathrm{CH})$ EUS can effectively differentiate mural nodules from clumps of mucin with low false-negative rates and is more accurate than fundamental B-mode EUS (specificity $75 \%$ vs $40 \%$ and accuracy $84 \%$ vs $64 \%$ ) [35]. It may also distinguish nodules with HGD or malignancy from low-grade dysplasia (LGD) [35, 36]. A large meta-analysis of 70 studies with 2,297 resected IPMNs showed that presence of nodules identified by CH-EUS had a $62.2 \%$ positive predictive value for $\mathrm{HGD} /$ invasive cancer [37]. Nodules taller than $5 \mathrm{~mm}$ seem more associated with malignancy although data regarding the implications of nodule size remain limited. CH-EUS may also help in identifying main duct involvement in BDIPMNs [38]. However, use of CH-EUS remains limited due to several factors: contrast agents remain not FDA approved for use in the pancreas; it is not widely available in the USA; and interobserver agreement remains low. The technique involves intravenous injection of a contrast agent to enhance the microvasculature differences between normal and abnormal tissues. Available agents include perflutren (Definity or Optison) for echocardiograms and sulfur hexafluoride (Lumason) for liver imaging. Following injection, benign lesions enhance to appear hyperechoic, whereas malignant tissues are under-perfused and hypoechoic.

Since EUS is more invasive, it is not recommended for all cysts. Most guidelines suggest the presence of at least one worrisome or high-risk feature before proceeding with EUS (Table 1) [4, 6, 7]. Other reasons to perform EUS include if diagnostic uncertainty remains despite high-quality imaging studies and if it will change management. EUS has ushered in a plethora of opportunities for diagnostic testing of cyst fluid via cytology, pathology, molecular, and chemical analyses (Table 3).

\section{Cyst Fluid Analysis}

\section{Cytology}

Endoscopic ultrasound-guided fine needle aspiration (EUSFNA) enables endosonographers to analyze cyst fluid in order to further characterize the PCL in question. The string sign is highly specific for mucinous lesions and can be performed by assessing cyst fluid dripping from the tip of the EUS needle or by placing a drop of fluid between 2 gloved fingers and pulling them apart [39]. It is defined as the fluid extending for at least $1 \mathrm{~cm}$ and $1 \mathrm{~s}$.

Lee et al. demonstrated that in a cohort of 603 patients, EUS-FNA is safe and well tolerated with a low complication rate of $2 \%$ [40]. Similar findings were reported in a large systematic review of 51 studies, including 10,941 patients, with $0.98 \%$ overall complication rate [41]. While rates of infection are very low with a recent noninferiority randomized controlled study confirming similar infection rates regardless of antibiotic prophylaxis, the American Society for Gastrointestinal Endoscopy recommends prophylactic antibiotics when performing EUS-FNA of pancreatic cysts
Table 3 Common EUS cyst fluid markers

\begin{tabular}{llll}
\hline Cyst fluid markers & Sensitivity & Specificity & Comments \\
\hline Cyst fluid cytology & $65 \%$ & $91 \%$ & For malignancy \\
Cyst fluid cytology & $54-63 \%$ & $88-93 \%$ & For mucinous cysts \\
CEA $>192 \mathrm{ng} / \mathrm{mL}$ & $75 \%$ & $84 \%$ & For mucinous cysts \\
CEA $<5 \mathrm{ng} / \mathrm{mL}$ & $50 \%$ & $95 \%$ & $\begin{array}{l}\text { For serous cystadenoma, cystic } \\
\text { neuroendocrine tumor, pseu- } \\
\text { docyst }\end{array}$ \\
Glucose $<50 \mathrm{mg} / \mathrm{dL}$ & & & For mucinous cysts, pseudocysts \\
Amylase $<250$ U/L & $89 \%$ to $92 \%$ & $75 \%$ to $86 \%$ & Excludes pseudocysts \\
KRAS/GNAS mutations & $44 \%$ & $98 \%$ & For mucinous cysts \\
\hline
\end{tabular}


with a fluoroquinolone or comparable antibiotic with similar coverage peri-procedure and then typically continued for 3 days $[42,43]$.

Cyst fluid cytology detects malignancy with high specificity (91\%) but similar to many other cyst fluid markers has low sensitivity (65\%) [44]. Two large meta-analyses confirmed similar sensitivity (54\% to $63 \%$ ) and specificity ( $88 \%$ to $93 \%$ ) for cytology in differentiating mucinous from nonmucinous cystic lesions [45, 46]. The main limitation with cytology is frequent insufficient material to render a diagnosis, which unfortunately occurs in over two-thirds of cases [47]. Performing FNA of the cyst wall after collapsing the cyst may improve diagnostic yield [48]. A recent small study suggested that EUS fine needle biopsy (FNB) provides superior diagnostic yield with acceptable complication rate [49].

\section{CEA}

Cyst fluid carcinoembryonic antigen (CEA) was the original cyst fluid marker discovered to differentiate mucinous from nonmucinous cysts using $192 \mathrm{ng} / \mathrm{ml}$ cutoff with $75 \%$ sensitivity and $84 \%$ specificity as described by Brugge et al. [33]. In a study of 776 patients, CEA levels in mucinous cysts $(4703 \mathrm{ng} / \mathrm{mL})$ were higher than nonmucinous cysts $(25.8 \mathrm{ng} / \mathrm{mL})$, and using a CEA cutoff value of $109.9 \mathrm{ng} / \mathrm{ml}$, sensitivity, specificity, and accuracy were $81 \%, 98 \%$, and $86 \%$, respectively. As the CEA cutoff is raised, the specificity improves at the expense of sensitivity. A systematic review of twelve studies (450 subjects) found levels greater than $800 \mathrm{ng} / \mathrm{mL}$ suggested a mucinous cyst with sensitivity and specificity of $48 \%$ and $98 \%$, respectively [50]. These different results likely reflect the fact that CEA levels vary depending on which assay is used. Extremely low CEA levels (less than $5 \mathrm{ng} / \mathrm{mL}$ ) had 50\% sensitivity and 95\% specificity for SCAs and pseudocyst. While elevated CEA levels can identify mucinous lesions, it is not useful for predicting malignancy [5]. Another limitation of CEA is the minimum volume of fluid required for analysis varies from 0.5 to $1 \mathrm{cc}$.

\section{Glucose}

Another biomarker that has been explored to diagnose mucinous lesions is intra-cystic glucose, which has been shown to have similar to superior diagnostic accuracy compared with CEA. A recent meta-analysis reported $91 \%$ sensitivity and $75 \%$ specificity for glucose compared with $67 \%$ sensitivity and $80 \%$ specificity for CEA [51]. The most common cutoff of less than $50 \mathrm{mg} / \mathrm{dl}$ suggests mucinous cysts with sensitivity ranging from 89 to $92 \%$ and specificity $75 \%$ to $86 \%$ [52-55]. Pseudocysts were also noted to have low glucose levels [53]. Low serum amylase $<250 \mathrm{U} / \mathrm{L}$ is highly specific for pseudocysts and may help diagnose pseudocysts when glucose is low. Advantages with glucose measurements include its low cost, rapid and simple measurement even using a glucometer, and small volumes (a few drops of fluid) needed. Whether accuracy for diagnosing mucinous cysts improves with the combination of glucose and CEA remains unclear.

\section{DNA-Based Testing}

Advances in molecular fluid analysis with DNA-based markers have gained considerable interest as a tool to differentiate mucinous from nonmucinous lesions, characterize mucinous subtypes (IPMN versus MCN), and detect grades of neoplasia. Since the epithelial lining of pancreatic cysts lyses and/or exfoliates DNA into the cyst fluid, assays for various DNA mutations may augment diagnostics. In a retrospective multicenter study, Springer et al. analyzed 130 resected cysts with their molecular sequencing panel, which identified cyst type with $76 \%$ to $100 \%$ sensitivity and $75 \%$ to $100 \%$ specificity depending on the specific cyst. This same panel correctly determined cysts needing surgery defined as solid pseudopapillary neoplasm, MCN, or IPMN with HGD or invasive cancer with $75 \%$ sensitivity and $92 \%$ specificity, which appears more specific than some guidelines [57, 58]. Another study of 225 patients reported their molecular panel testing (KRAS, GNAS, VHL, TP53, PIK3CA, and PTEN) detected advanced neoplasias with a sensitivity and specificity of $100 \%$ and $90 \%$, respectively [58].

For identifying mucinous PCLs, KRAS and GNAS mutations have emerged as reliable markers. In a preoperative prospective study of 626 fluid samples using next-generation sequencing, Singhi et al. found that KRAS and GNAS mutations were $89 \%$ sensitive and $100 \%$ specific for mucinous cysts. Furthermore, presence of KRAS and/or GNAS mutations was $100 \%$ sensitive for IPMN while GNAS mutations were $100 \%$ specific for IPMN [59-61]. A recent meta-analysis reported that KRAS and GNAS mutations were more accurate for identifying mucinous cysts than CEA alone [62].

While GNAS mutations are not found in MCNs, KRAS mutations appear to increase in prevalence with advancing degrees of dysplasia in MCN with one older surgical pathology study reporting a detection rate of $26 \%$ in LGD, $38 \%$ in moderate dysplasia, and $89 \%$ in HGD or invasive cancer [61]. A recent small study of resected MCNs confirmed higher frequency of KRAS mutations associated with HGD and invasive cancer [63].

On the other end of the spectrum, SCAs do not contain these mutations; instead, VHL mutations and/or deletions occur in $89 \%$ to $100 \%$ of SCAs $[56,64]$. Promisingly, DNA analyses of SMAD4, CDKN2A, TP53, PIK3CA, and PTEN have also been associated with neoplasia [16]. While molecular analysis is costly with uncertain ability to predict cancer 
risk, it may prove useful when diagnosis remains unclear and a definitive diagnosis would alter management.

\section{EUS-Guided-Through-the-Needle-Biopsy}

Given the diagnostic limitations of cytology and cyst fluid analysis, interest has blossomed for EUS-guided throughthe-needle biopsy (TTNB), which offers the possibility of the holy grail of pathology. One such disposable device, a microbiopsy forceps (Moray micro forceps; Steris Healthcare, Mentor, Ohio), is advanced through a 19 -gauge needle during EUS-FNA to acquire pinch biopsies of the cyst wall and/or mural nodules. Similar technique may be used with the SpyBite biopsy forceps (Boston Scientific, Marlborough, MA) although there is only a case report using this device [65]. The optimal technique for microbiopsy forceps may be two separate biopsy bites with tenting, which produced $74 \%$ diagnostic accuracy [66]. Expert pathologists have substantial to near-perfect agreement when evaluating specimens from microbiopsy forceps [67]. A recent meta-analysis of 9 studies with 454 patients reported diagnostic yield of $69.5 \%$ and $88.6 \%$ sensitivity for differentiating mucinous from nonmucinous lesions [68]. Technical success is high $(86 \%$ to $100 \%)$ [69-71].

This technique appears to have superior diagnostic yield compared to FNA cytology [72-76]. A meta-analysis of 8 studies with 426 patients noted that TTNB histology was more likely to diagnose the specific type of cyst $(72.5 \%)$ than FNA cytology $(38.1 \%)$ as well as mucinous cysts $(56.2 \% \mathrm{v}$. $29.5 \%)$ and SCAs (12.4\% v. 1.2\%) [77]. Analysis of surgically resected samples in a retrospective study noted $90 \%$ concordance with TTNB histology compared with only $20 \%$ concordance with FNA cytology [66]. A small comparative study between microbiopsy forceps and conventional analysis (CEA level, cytology, and molecular testing via nextgeneration sequencing) noted that microbiopsy forceps and standard of care were comparable for identifying mucinous cysts while microbiopsy forceps were superior in diagnosing the specific type of cyst [78].

Despite these findings, there a few limitations to highlight. First, the number of passes needed to acquire adequate samples is not standardized and likely led to varying diagnostic yields and complications. Only one study has examined this issue reaching the conclusion that two separate passes are sufficient [66] while other studies have ranged from performing 1 to 5 passes [71-76, 78, 79]. Also, while diagnostic yield appears significantly improved compared to FNA cytology, it remains modest likely due to sampling issues. The histology samples may not accurately reflect the pathology of the entire cyst in question. A combination of techniques may be necessary to improve diagnostic yield further. Most importantly, adverse events remain a concern. One technical review noted complications ranging from 2 to
$23 \%$ [80] with meta-analyses reporting a pooled estimate of $7 \%$ to $8.6 \%[68,77]$. A recent prospective study pointed out that although management was changed in $11.9 \%$ of cases due to the TTNB results (mostly due to diagnosing SCA), a relatively high rate of complications occurred in 9.9\% (10 patients), of which $90 \%$ were pancreatitis and $40 \%$ severe with 1 death [81]. Therefore, while TTNB is an exciting adjunctive tool in diagnosing pancreatic cystic lesions, the potential for serious adverse events must be weighed against a condition that for most patients will be benign. Further studies are needed to understand when the potential benefits of TTNB in changing management beyond the standard tools of cytology or pathology and cyst fluid analyses outweigh the potential risks.

\section{EUS-Guided Needle-Based Confocal Laser Endomicroscopy}

Needle-based confocal laser endomicroscopy (nCLE) is a novel optical biopsy technique that employs a mini-CLE probe advanced through a 19-gauge needle during EUSFNA to capture in vivo microscopic images of the cyst's epithelial lining [82]. Intravenous fluorescein is necessary to enhance blood vessels and surrounding structures. Lowpowered laser light is reflected and filtered from the tissue of interest and reconfigured through a computer algorithm to provide magnified, high-resolution images [83].

For distinguishing mucinous from nonmucinous cysts, diagnostic accuracy of EUS-nCLE appears superior to CEA (96\% v. 64\%) or cytology[84, 85] Papillary projections and/ or dark rings which are cross-sectional views of the papillae are consistent with IPMNs [86] while thick gray lines are epithelial bands representing MCNs (Fig. 5) [87]. SCAs have a characteristic nCLE finding of a superficial vascular network pattern that microscopically corresponds to dense subepithelial capillaries (Fig. 6) [88]. Studies confirm 97\% specificity and $87 \%$ sensitivity for diagnosing SCA with this nCLE criteria [85]. One study suggested EUS-nCLE was more accurate than CEA for diagnosing SCA [89]. Cystic neuroendocrine tumors also have very low CEA values, and limited data suggest nCLE may accurately identify these lesions [85]. Findings on EUS-nCLE include dark clumps of cells surrounded by gray areas representing fibrous and vascular areas [87].

A recent study suggests that EUS-nCLE may differentiate LGD IPMNs from IPMNs with HGD or invasive cancer. Papillary width at least $50 \mu \mathrm{m}$ and papillary darkness (cutoff $\leq 90$ pixel density) were associated with HGD or invasive cancer, both with $87.5 \%$ sensitivity and $100 \%$ specificity [90]. Multicenter validation of these criteria will be needed. Artificial intelligence may aid with detection and diagnosis during nCLE. By using convolutional neural network to develop two computer-aided diagnosis algorithms that 


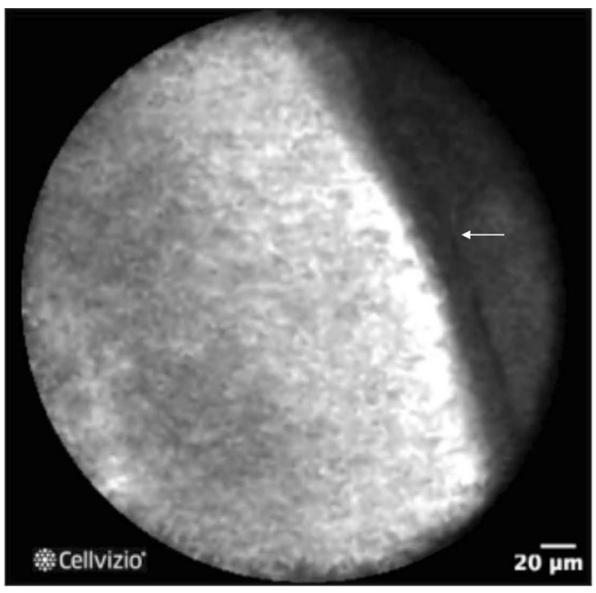

Fig. 5 Epithelial band in mucinous cystic neoplasm. Courtesy of Dr. Bertrand Napoléon, CONTACT trials

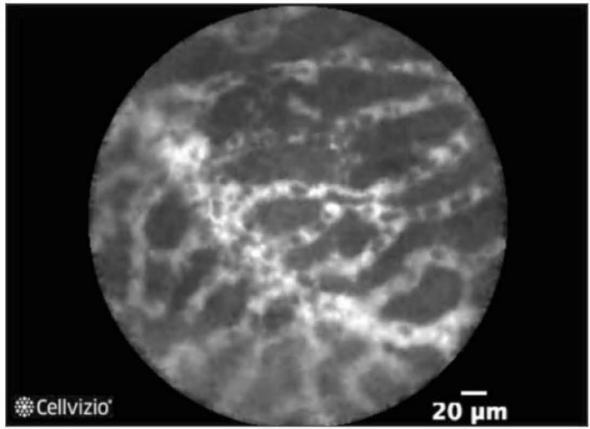

Fig. 6 Superficial vascular network in serous cystadenoma. Courtesy of Mauna Kea Technologies

detected and measured the papillary width and darkness or incorporated various nCLE features, Machicado et al. recently demonstrated improved ability to diagnose HGD and cancer in IPMNs (82.9\% and 85.7\% accuracy) compared with the Fukuoka (74.3\%) or AGA (68.6\%) guidelines [91]. Clearly, the impact of artificial intelligence in pancreatic cysts will continue to evolve as the technology does.

There are some varying reports of interobserver agreement for EUS-nCLE. Apart from an outlier study that reported poor to fair global interobserver agreement with mean diagnostic accuracy of only $46 \%$ (ranging from 20 to $67 \%$ )[92], other studies have suggested moderate to substantial agreement for identifying mucinous cysts and substantial to almost perfect agreement for SCAs [87, 92-94]. Some critiques of the Karia et al. study[92] include short video clips, few patients with surgical pathology confirmed diagnoses, and assessment of findings that are not the validated criteria for various PCLs [85].

Adverse events from EUS-nCLE range from 0 to $9 \%$ with a pooled $2.9 \%$ risk of acute pancreatitis with 1 severe case
[85, 86, 95]. To minimize post-procedure pancreatitis, these techniques are recommended although confirmatory studies are lacking to prove their efficacy in reducing risk: (1) Keep duration of nCLE as short as possible and minimize catheter manipulation. As soon as diagnostic nCLE criteria are visualized, the probe should be removed; (2) Perform EUS-nCLE for no longer than $6 \mathrm{~min}$; (3) Do not brush the tip of nCLE catheter across the epithelial surface to interrogate a different area. Instead, pull the instrument back, and then, gently place the catheter tip on the new area as perpendicular as possible to the epithelial surface [85]. Despite using this technique, a limitation of nCLE is that the entire cyst wall cannot be visualized (at best, approximately 30\% to 50\% can be scanned) [96] . However, the same limitation occurs with performing EUSTTNB. A single-center retrospective study compared standard of care (clinical, morphologic, cyst fluid cytology, and CEA analysis) to TTNB and nCLE, noting that diagnostic yield for each modality (75\% and $84.1 \%$, respectively) was greater than standard of care (34.1\%) [97]. Combining either or both techniques with standard of care led to similar diagnostic yields. An issue with this study is that other cyst fluid markers including glucose, amylase, and DNA markers were not incorporated in the standard of care arm.

The place of EUS-nCLE in the algorithm for evaluating PCLs remains to be determined. While studies have suggested its superior accuracy compared with CEA or cytology, no studies have compared all the available cyst fluid markers of CEA, glucose, DNA markers, and FNB to nCLE. Different approaches may be taken for incorporating nCLE into practice: EUS-nCLE may be performed in all patients with indeterminate cysts undergoing EUS or selectively following an initial nondiagnostic EUS-FNA. Wide dissemination of this technology remains limited due to need for training and costs. Endosongraphers must be competent in pancreatic EUS and EUS-FNA before training in nCLE. The recent expert consensus statement recommends a minimum of 10 supervised procedures to achieve competency and ongoing annual performance of at least 10 EUS-nCLE to maintain competence [85]. Adverse events like pancreatitis have been shown to decrease with increased operator experience [94]. A health economic evaluation of nCLE in France reported that EUS-FNA plus nCLE could reduce $23 \%$ of surgeries which would translate into a $13 \%$ reduction in clinical costs in the public sector [98]. However, further studies are needed to understand both the optimal clinical niche and financial implications of nCLE.

\section{Approach to Pancreatic Cyst}

Despite these advances in diagnostic techniques, managing PCLs is a constantly evolving topic that revolves around stratifying the malignant potential of the cyst. The authors' 
suggested algorithm for approaching incidental pancreatic cysts provides a framework for approaching these lesions (Fig. 7). However, before proceeding with this management paradigm, it is important to determine if the patient even requires further evaluation-Are they medically fit for surgery or is the cyst an asymptomatic non-neoplastic (pseudocyst) or benign lesion (SCA) that requires no follow up? Patients with IPMNs and high Charlson Comorbidity Index ( $\geq 7)$ had significantly shorter survival (43 months) compared to 180 months for patients with lower scores and had an 11-fold higher risk of dying from non-IPMN-related causes within 3 years [99]. A similar study using the Charlson Comorbidity Index noted that high-risk patients with low-risk cysts were more likely to die from non-pancreatic cancer [100]. Another scoring system (Adult Comorbidity Evaluation 27) was used in a study of 793 patients with IPMNs and reached similar conclusions that patients with higher scores were more likely to die from non-IPMNrelated causes [101]. Thus, these scoring systems may assist clinical decision-making when significant comorbidities are present.

The AGA guideline with its controversial recommendation to stop surveillance after 5 years of stability engendered a flurry of long-term studies of pancreatic cysts. A longterm retrospective study found a very low rate of malignant progression $(0.9 \%)$ for $108 \mathrm{BD}-\mathrm{IPMN} \leq 1.5 \mathrm{~cm}$ that were followed for more than 5 years [102]. However, another study following BD-IPMNs without worrisome or high-risk features for a minimum of 5 years showed that worrisome or high-risk features developed in 18\% of BD-IPMNs well beyond 5 years of observation [103]. Similar findings were observed in a cohort of 1,036 BD-IPMNs without worrisome features in which $4 \%$ and $1 \%$ of cysts developed worrisome features and pancreatic cancer, respectively, after a median 62 months [104]. In light of these studies, surveillance cannot end in all patients after 5 years, and whether there is a subset of patients in whom surveillance may be safely stopped requires further investigation.

While no study has yet proved reduction in mortality with surveillance, the risk of malignancy cannot be ignored, and it is critical that shared decision-making with the patient is pursued when offering surveillance. Issues to consider include (1) the psychological distress associated with annual surveillance and (2) the significant financial burden to the health-care system. One study estimated that if all patients with cysts (aged 40-79) underwent MRI surveillance, the median cost would be $\$ 9.3$ billion per year [105]. These calculations did not factor in the cost of surgery or EUS. There is also the concern that patients can be lost to follow up with recent studies finding that $47 \%$ to $71.5 \%$ of patients received follow-up imaging for incidental cysts [106, 107]. In a large urban safety net hospital, access to gastroenterology care was associated with surveillance completion [106]. More specifically, referral to a multidisciplinary pancreas group is recommended for cysts with any concerning features and when considering surgical resection as evaluation

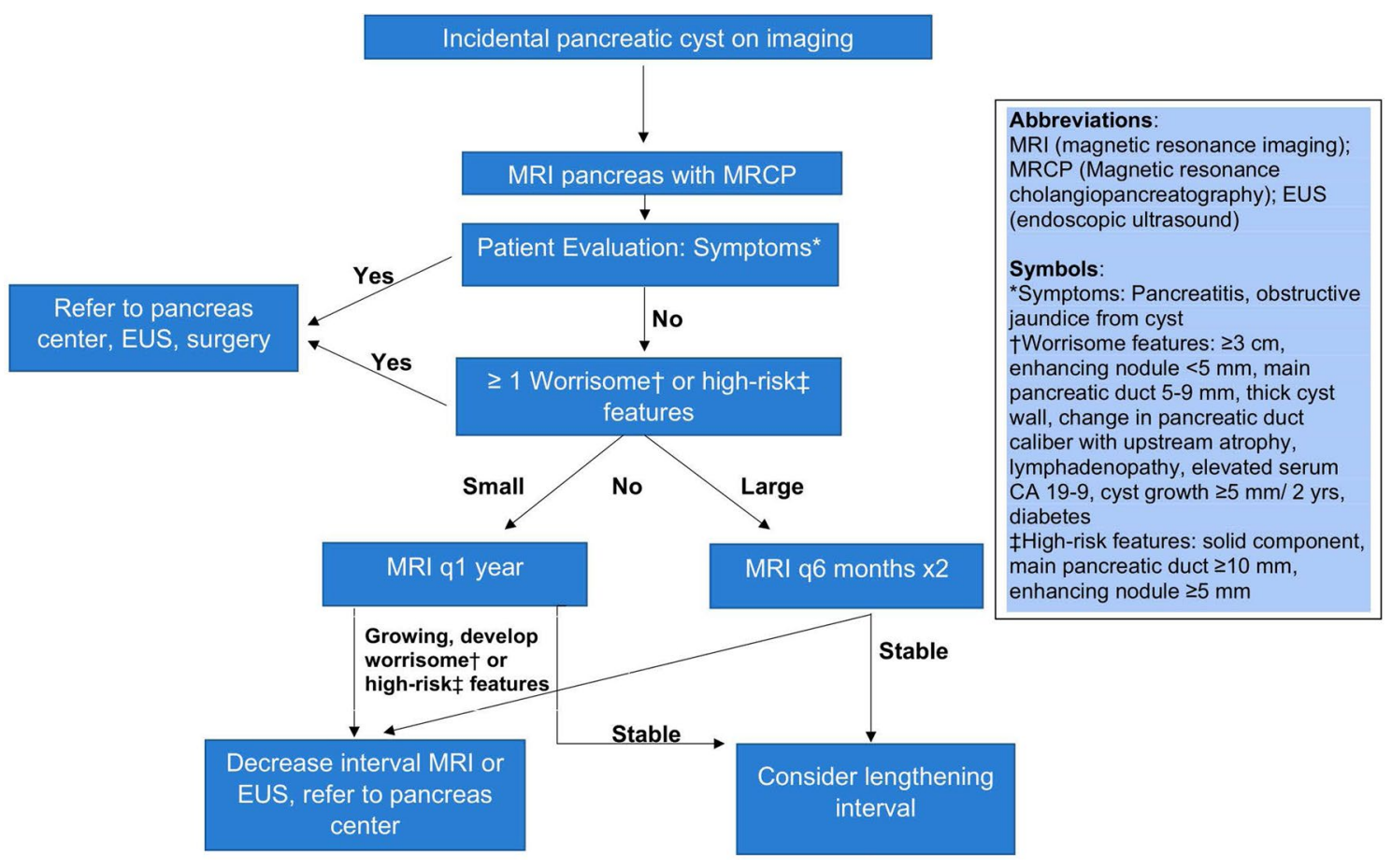

Fig. 7 Incidental Pancreatic Cyst Management Algorithm 
by such a center changed management in $30 \%$ of patients away from surgery and toward surveillance [108]. Pancreatic resection should be performed by experienced surgeons at these high-volume centers due to significantly lower postsurgical mortality rates (1-5\%) compared with low-volume centers $(11-15 \%)[4,6]$.

Patient education about their cysts is important as a survey found that $96 \%$ of patients were unaware of their specific cyst type and 58\% did not realize some cysts had malignant potential [109]. Physicians need to help patients understand the risks and benefits of pursuing imaging surveillance.

\section{EUS-Guided Ablation Techniques}

The need for minimally invasive treatment of PCLs has led to the development of EUS-guided cyst ablation, designed to destroy the neoplastic epithelial lining of the cyst in patients who decline or are not operative candidates. Cyst ablation can be achieved by the injection of ethanol, antitumor agents (paclitaxel), or radiofrequency ablation (RFA). Although in its infancy, EUS-guided ablation has been shown to resolve cysts in $33 \%$ to $79 \%$ of cases while also improving quality of life by avoiding surgery [10]. Moreover, propensity score matching analysis found that compared to PCLs undergoing surveillance initially $(n=428)$, the EUS alcohol ablation group $(n=118)$ had significantly lower surgical resection rates $(4.8 \%$ vs $26.2 \%)$ with similar survival over mean follow-up of over 6 years [110].

Patients eligible for cyst ablation by injection of ethanol or antitumor agents include those with a mucinous cyst larger than $3 \mathrm{~cm}$ or over $2 \mathrm{~cm}$ and growing while malignancy and short life expectancies are contraindications [10, 111-113]. Ideal cysts for EUS-guided ablation have the following features: unilocular or oligolocular (less than 7 locules) to ensure each locule is injected appropriately [10]; cyst size $2-6 \mathrm{~cm}$; and no open communication with the main pancreatic duct.

Response to ablation is defined by volume reduction in the cyst, which is susceptible to variations in cyst measurement even when using the same modality pre- and postprocedure. Complete response is defined as at least $95 \%$ reduction in volume, partial response as $75 \%$ to $95 \%$, and non-response as $0 \%$ to $74 \%$ [113].

\section{EUS-Guided Alcohol Ablation}

As a widely available, inexpensive, low-viscosity agent with quick onset of action, ethanol is an effective ablative agent to treat cystic lesions throughout the body [112]. Shortly after injection, it induces cell membrane lysis, protein denaturation, and vascular occlusion [10]. Studies using ethanol ablation to treat PCLs have reported complete resolution rates ranging from 9 to $85 \%$ [114-119]. This wide range is likely related to different study designs, techniques, types of cysts treated, and levels of ethanol concentration used, which varied from 80 to $100 \%$. In addition to the wide variability in outcome, adverse events range from $3.3 \%$ to $33.2 \%$ with pancreatitis occurring in 3.3\% to $9.8 \%$ [118-120]. These studies raise concern over the long-term efficacy and safety of ethanol ablation. EUS-Guided Alcohol and Paclitaxel Ablation:

As a chemotherapeutic agent, paclitaxel is highly viscous and hydrophobic and can theoretically remain in the cyst for a long time to exert its apoptotic effects along the epithelial lining. A prospective study of 164 patients who underwent cyst ablation with alcohol and paclitaxel reported complete resolution, partial resolution, and persistent cyst in $72 \%, 20 \%$, and $8 \%$, respectively [121]. The 114 patients with complete resolution were followed for 6 years with only $1.7 \%$ cyst recurrence [121]. Cyst diameter $<35 \mathrm{~mm}$ [122] and absence of septa [121] were predictors of complete resolution. Needle punctures through septa can improve ablative outcomes while minimizing adverse events [123]. Interestingly, DeWitt and colleagues found that baseline DNA mutations can be eliminated in $72 \%$ of post-ablation cyst fluid [124].

This combination therapy has replaced ethanol as the preferred approach for cyst ablation both due to increased efficacy and decreased complications [121-128]. Pooled adverse events are lower for paclitaxel-based regiments (15\%) compared to ethanol lavage (21.7\%) [129]. Pancreatitis has been attributed to the extravasation of ethanol. Therefore, the question that naturally follows is whether alcohol is necessary for cyst ablation and whether adverse events can be reduced without alcohol. In a randomized trial comparing paclitaxel and gemcitabine with and without $80 \%$ ethanol, all adverse events occurred in the alcohol group (22\% minor and $6 \%$ serious events) [128]. Complete ablation occurred at similar rates in both groups $(67 \%$ in alcohol-free versus $61 \%$ in alcohol control group). A larger NIH-funded study is ongoing to validate these findings [130]. Future studies may lead to the development of new delivery agents, improved techniques, and standardized definitions of clinical success that will hopefully broaden the application of EUS-guided cyst ablation.

\section{Radiofrequency Ablation}

Radiofrequency ablation (RFA) is a safe, effective, and wellestablished technique used to treated cystic lesions (such as in the thyroid and kidney) $[131,132]$. Currently only a 19-gauge EUS-guided RFA needle is available to induce direct cell death via coagulative necrosis and hyperthermic energy [133, 134]. This necrotic cascade releases intracellular antigens that activates a systemic immune response (hours to days following the procedure) [135]. Only a few 
studies have investigated the role of EUS-RFA in treating PCLs [133, 134].

In 2015, Pai and colleagues conducted a preliminary study of EUS-RFA in which all 6 PCLs were treated successfully with 2 cysts having complete resolution and 3 demonstrating a 48.4\% size reduction 3-6 months later [134]. There were no major adverse events and only two cases of mild self-limited abdominal pain. A larger prospective study by Barthet et al. treated and followed 16 BD-IPMNs and 1 MCN over a 1-year period [133]. The overall rate of adverse events was $10 \%$, but a modified protocol decreased the complication rate to $3.5 \%$. Pancreatitis complicated by infection and jejunal perforation occurred in the first two study participants. Subsequent protocol modifications of using rectal diclofenac, antibiotics, and cyst fluid aspiration prior to RFA led to only one subsequent complication (pancreatic duct stenosis). Among the 17 PCLs, complete resolution at 6 and 12 months occurred in $47 \%$ and $64.7 \%$, respectively. This delayed response may be secondary to the immunostimulatory effects of RFA. In one small study of SCAs, EUS-RFA led to $61.5 \%$ radiologic response with median volume of cysts decreasing from $37.82 \mathrm{~mL}$ to $10.95 \mathrm{~mL}$ [136]. Clearly, larger- and longer-term studies are needed to further assess the efficacy and safety of EUS-RFA in pancreatic cysts.

\section{Conclusion}

Pancreatic cysts remain a diagnostic and management challenge to clinicians and require shared decision-making with patients and occasionally a multidisciplinary approach. While the majority of cysts may be followed with MRI likely without gadolinium, careful appreciation for when to stop surveillance in higher-risk patients, when to refer for EUS in the presence of worrisome or high-risk features or indeterminate cysts, and when to consider surgical resection is essential. The exciting potential of newer diagnostic tools including through the needle biopsy and needle-based confocal laser endomicroscopy as well as novel therapeutics with EUS-guided ablation techniques requires further study.

\section{Key Findings and Unmet Needs}

1. Pancreatic cystic lesions are commonly discovered due to advances in cross-sectional imaging and increased use of abdominal imaging and often represent a diagnostic dilemma for clinicians.

2. Risk stratifying the malignant potential of an incidental pancreatic cyst to determine the optimal next steps requires an individualized approach informed by the guidelines, with some patients benefiting from referral to multidisciplinary pancreas centers.
3. Advances in molecular fluid analysis with DNA-based markers have gained considerable attention as a tool to diagnose mucinous lesions with further work necessary to determine the optimal markers for predicting grades of neoplasia.

4. On the other hand, measuring the humble cyst fluid glucose level also appears to improve identification of mucinous cysts.

5. Newer endoscopic ultrasound-based diagnostic tools, needle-based confocal laser endomicroscopy and microbiopsy forceps, are exciting, but require further study regarding their safety profile and role in the diagnostic algorithm.

6. Endoscopic ultrasound ablation techniques have led to varying degrees of cyst resolution, but further study is necessary to determine the optimal technique and longterm durability.

Disclosures There are no relevant disclosures.

\section{Declarations}

Conflict of interest Each author listed has no potential conflicts (financial, professional, or personal) that are relevant to the content presented in this manuscript.

Open Access This article is licensed under a Creative Commons Attribution 4.0 International License, which permits use, sharing, adaptation, distribution and reproduction in any medium or format, as long as you give appropriate credit to the original author(s) and the source, provide a link to the Creative Commons licence, and indicate if changes were made. The images or other third party material in this article are included in the article's Creative Commons licence, unless indicated otherwise in a credit line to the material. If material is not included in the article's Creative Commons licence and your intended use is not permitted by statutory regulation or exceeds the permitted use, you will need to obtain permission directly from the copyright holder. To view a copy of this licence, visit http://creativecommons.org/licenses/by/4.0/.

\section{References}

1. Tanaka M, Fernández-del Castillo C, Adsay V et al. International consensus guidelines 2012 for the management of IPMN and MCN of the pancreas. Pancreatol Off J Int Assoc Pancreatol IAP Al 2012;12:183-197.

2. Tanaka M, Fernández-Del Castillo C, Kamisawa T et al. Revisions of international consensus Fukuoka guidelines for the management of IPMN of the pancreas. Pancreatol Off J Int Assoc Pancreatol IAP Al 2017;17:738-753.

3. European evidence-based guidelines on pancreatic cystic neoplasms. Gut 2018;67:789-804.

4. Vege SS, Ziring B, Jain R, et al. American gastroenterological association institute guideline on the diagnosis and management of asymptomatic neoplastic pancreatic cysts. Gastroenterology 2015; 148: 819-822; quize12-13. 
5. Scheiman JM, Hwang JH, Moayyedi P. American gastroenterological association technical review on the diagnosis and management of asymptomatic neoplastic pancreatic cysts. Gastroenterology 2015;148:824-848.e22.

6. Elta GH, Enestvedt BK, Sauer BG et al. ACG clinical guideline: diagnosis and management of pancreatic cysts. Am J Gastroenterol 2018;113:464-479.

7. Megibow AJ, Baker ME, Morgan DE et al. Management of incidental pancreatic cysts: a white paper of the ACR incidental findings committee. J Am Coll Radiol JACR 2017;14:911-923.

8. de Jong K, Nio CY, Hermans JJ et al. High prevalence of pancreatic cysts detected by screening magnetic resonance imaging examinations. Clin Gastroenterol Hepatol Off Clin Pract J Am Gastroenterol Assoc 2010;8:806-811.

9. Lee KS, Sekhar A, Rofsky NM et al. Prevalence of incidental pancreatic cysts in the adult population on MR imaging. Am J Gastroenterol 2010;105:2079-2084.

10. Canakis A, Law R, Baron T. An updated review on ablative treatment of pancreatic cystic lesions. Gastrointest Endosc 2020;91:520-526.

11. Kimura W, Nagai H, Kuroda A et al. Analysis of small cystic lesions of the pancreas. Int J Pancreatol Off J Int Assoc Pancreatol 1995;18:197-206.

12. Abdelkader A, Hunt B, Hartley CP et al. Cystic lesions of the pancreas: differential diagnosis and cytologic-histologic correlation. Arch Pathol Lab Med 2020;144:47-61.

13. Jais B, Rebours V, Malleo G et al. Serous cystic neoplasm of the pancreas: a multinational study of 2622 patients under the auspices of the International Association of Pancreatology and European Pancreatic Club (European Study Group on Cystic Tumors of the Pancreas). Gut 2016;65:305-312.

14. Crippa S, Salvia R, Warshaw AL et al. Mucinous cystic neoplasm of the pancreas is not an aggressive entity: lessons from 163 resected patients. Ann Surg 2008;247:571-579.

15. Park JW, Jang J-Y, Kang MJ et al. Mucinous cystic neoplasm of the pancreas: is surgical resection recommended for all surgically fit patients? Pancreatol Off J Int Assoc Pancreatol IAP Al 2014;14:131-136.

16. van Huijgevoort NCM, Del Chiaro M, Wolfgang CL et al. Diagnosis and management of pancreatic cystic neoplasms: current evidence and guidelines. Nat Rev Gastroenterol Hepatol 2019;16:676-689.

17. Jang K-T, Park SM, Basturk O et al. Clinicopathologic characteristics of 29 invasive carcinomas arising in 178 pancreatic mucinous cystic neoplasms with ovarian-type stroma. Am J Surg Pathol 2015;39:179-187.

18. Gil E, Choi SH, Choi DW et al. Mucinous cystic neoplasms of the pancreas with ovarian stroma. ANZ J Surg 2013;83:985-990.

19. Sahora K, Fernández-del Castillo C, Dong F et al. Not all mixed-type intraductal papillary mucinous neoplasms behave like main-duct lesions: Implications of minimal involvement of the main pancreatic duct. Surgery 2014;156:611-621.

20. Crippa S, Bassi C, Salvia R et al. Low progression of intraductal papillary mucinous neoplasms with worrisome features and high-risk stigmata undergoing non-operative management: a mid-term follow-up analysis. Gut 2017;66:495-506.

21. Pergolini I, Schorn S, Jäger C et al. Diabetes mellitus in intraductal papillary mucinous neoplasms: a systematic review and meta-analysis. Surgery 2021;169:411-418.

22. Maggi G, Guarneri G, Gasparini G et al. Pancreatic cystic neoplasms: what is the most cost-effective follow-up strategy? Endosc Ultrasound 2018;7:319-322.

23. Jones MJ, Buchanan AS, Neal CP et al. Imaging of indeterminate pancreatic cystic lesions: a systematic review. Pancreatol Off J Int Assoc Pancreatol IAP Al 2013;13:436-442.
24. Expert Panel on Gastrointestinal Imaging, Fábrega-Foster K, Kamel IR, et al. ACR Appropriateness Criteria ${ }^{\circledR}$ Pancreatic Cyst. J Am Coll Radiol JACR 2020; 17: S198-S206.

25. Sainani NI, Saokar A, Deshpande V et al. Comparative performance of MDCT and MRI with MR cholangiopancreatography in characterizing small pancreatic cysts. AJR Am J Roentgenol 2009;193:722-731.

26. Runge VM. Critical questions regarding gadolinium deposition in the brain and body after injections of the gadoliniumbased contrast agents, safety, and clinical recommendations in consideration of the EMA's Pharmacovigilance and risk assessment committee recommendation for suspension of the marketing authorizations for 4 linear agents. Invest Radiol 2017;52:317-323.

27. Macari M, Lee T, Kim S et al. Is gadolinium necessary for MRI follow-up evaluation of cystic lesions in the pancreas? Preliminary results. AJR Am J Roentgenol 2009;192:159-164.

28. Rastegar N, Matteoni-Athayde LG, Eng J et al. Incremental value of secretin-enhanced magnetic resonance cholangiopancreatography in detecting ductal communication in a population with high prevalence of small pancreatic cysts. Eur J Radiol 2015;84:575-580.

29. Serafini S, Sperti C, Brazzale AR et al. The role of positron emission tomography in clinical management of intraductal papillary mucinous neoplasms of the pancreas. Cancers. 2020. https://doi. org/10.3390/cancers12040807.

30. Srinivasan N, Koh Y-X, Goh BKP. Systematic review of the utility of 18-FDG PET in the preoperative evaluation of IPMNs and cystic lesions of the pancreas. Surgery 2019;165:929-937.

31. Kauhanen S, Rinta-Kiikka I, Kemppainen J et al. Accuracy of 18F-FDG PET/CT, Multidetector CT, and MR imaging in the diagnosis of pancreatic cysts: a prospective single-center study. J Nucl Med Off Publ Soc Nucl Med 2015;56:1163-1168.

32. Visser BC, Yeh BM, Qayyum A et al. Characterization of cystic pancreatic masses: relative accuracy of CT and MRI. AJR Am J Roentgenol 2007;189:648-656.

33. Brugge WR, Lewandrowski K, Lee-Lewandrowski E et al. Diagnosis of pancreatic cystic neoplasms: a report of the cooperative pancreatic cyst study. Gastroenterology 2004;126:1330-1336.

34. Zhong N, Zhang L, Takahashi $\mathrm{N}$ et al. Histologic and imaging features of mural nodules in mucinous pancreatic cysts. Clin Gastroenterol Hepatol 2012;10:192-198.e2.

35. Kamata K, Kitano M, Omoto S et al. Contrast-enhanced harmonic endoscopic ultrasonography for differential diagnosis of pancreatic cysts. Endoscopy 2016;48:35-41.

36. Yamamoto N, Kato H, Tomoda T et al. Contrast-enhanced harmonic endoscopic ultrasonography with time-intensity curve analysis for intraductal papillary mucinous neoplasms of the pancreas. Endoscopy 2016;48:26-34.

37. Marchegiani G, Andrianello S, Borin A et al. Systematic review, meta-analysis, and a high-volume center experience supporting the new role of mural nodules proposed by the updated 2017 international guidelines on IPMN of the pancreas. Surgery 2018:163:1272-1279.

38. Ohno E, Kawashima H, Ishikawa T et al. Can contrast-enhanced harmonic endoscopic ultrasonography accurately diagnose main pancreatic duct involvement in intraductal papillary mucinous neoplasms? Pancreatol Off J Int Assoc Pancreatol IAP Al 2020;20:887-894.

39. Bick BL, Enders FT, Levy MJ et al. The string sign for diagnosis of mucinous pancreatic cysts. Endoscopy 2015;47:626-631.

40. Lee LS, Saltzman JR, Bounds BC et al. EUS-guided fine needle aspiration of pancreatic cysts: a retrospective analysis of complications and their predictors. Clin Gastroenterol Hepatol Off Clin Pract J Am Gastroenterol Assoc 2005;3:231-236. 
41. Wang K-X, Ben Q-W, Jin Z-D et al. Assessment of morbidity and mortality associated with EUS-guided FNA: a systematic review. Gastrointest Endosc 2011;73:283-290.

42. Colán-Hernández J, Sendino O, Loras C et al. Antibiotic prophylaxis is not required for endoscopic ultrasonography-guided fine-needle aspiration of pancreatic cystic lesions. Based on a Randomized Trial. Gastroenterology 2020;158:1642-1649.e1.

43. Khashab MA, Chithadi KV, Acosta RD et al. Antibiotic prophylaxis for GI endoscopy. Gastrointest Endosc 2015;81:81-89.

44. Suzuki R, Thosani N, Annangi S et al. Diagnostic yield of EUS-FNA-based cytology distinguishing malignant and benign IPMNs: a systematic review and meta-analysis. Pancreatol Off $J$ Int Assoc Pancreatol IAP Al 2014;14:380-384.

45. Thornton GD, McPhail MJW, Nayagam $S$ et al. Endoscopic ultrasound guided fine needle aspiration for the diagnosis of pancreatic cystic neoplasms: a meta-analysis. Pancreatol Off J Int Assoc Pancreatol IAP Al 2013;13:48-57.

46. Thosani N, Thosani S, Qiao W et al. Role of EUS-FNA based cytology in diagnosis of mucinous pancreatic cystic lesions: a systematic review and meta-analysis. Dig Dis Sci 2010;55:2756-2766.

47. de Jong K, Poley J-W, van Hooft JE et al. Endoscopic ultrasound-guided fine-needle aspiration of pancreatic cystic lesions provides inadequate material for cytology and laboratory analysis: initial results from a prospective study. Endoscopy 2011;43:585-590.

48. Hong S-KS, Loren DE, Rogart JN et al. Targeted cyst wall puncture and aspiration during EUS-FNA increases the diagnostic yield of premalignant and malignant pancreatic cysts. Gastrointest Endosc 2012;75:775-782.

49. Phan J, Dawson D, Sedarat A et al. Clinical utility of obtaining endoscopic ultrasound-guided fine-needle biopsies for histologic analyses of pancreatic cystic lesions. Gastroenterology 2020;158:475-477.e1.

50. van der Waaij LA, van Dullemen HM, Porte RJ. Cyst fluid analysis in the differential diagnosis of pancreatic cystic lesions: a pooled analysis. Gastrointest Endosc 2005;62:383-389.

51. Faias S, Cravo MM, Chaves $P$ et al. A comparative analysis of glucose and carcinoembryonic antigen in diagnosis of pancreatic mucinous cysts a systematic review and meta-analysis. Gastrointest Endosc. 2021. https://doi.org/10.1016/j.gie.2021.01.021.

52. Carr RA, Yip-Schneider MT, Simpson RE et al. Pancreatic cyst fluid glucose: rapid, inexpensive, and accurate diagnosis of mucinous pancreatic cysts. Surgery 2018;163:600-605.

53. Faias S, Pereira L, Roque R et al. Excellent accuracy of glucose level in cystic fluid for diagnosis of pancreatic mucinous cysts. Dig Dis Sci 2020;65:2071-2078.

54. Ribaldone DG, Bruno M, Gaia S et al. Differential diagnosis of pancreatic cysts: a prospective study on the role of intra-cystic glucose concentration. Dig Liver Dis Off J Ital Soc Gastroenterol Ital Assoc Study Liver 2020;52:1026-1032.

55. Simons-Linares CR, Yadav D, Lopez R et al. The utility of intracystic glucose levels in differentiating mucinous from nonmucinous pancreatic cysts. Pancreatol Off J Int Assoc Pancreatol IAP Al 2020;20:1386-1392.

56. Springer S, Wang Y, Molin MD et al. A combination of molecular markers and clinical features improve the classification of pancreatic cysts. Gastroenterology 2015;149:1501-1510.

57. Lee A, Kadiyala V, Lee LS. Evaluation of AGA and fukuoka guidelines for EUS and surgical resection of incidental pancreatic cysts. Endosc Int Open 2017;5:E116-E122.

58. Singhi AD, Zeh HJ, Brand RE et al. American gastroenterological association guidelines are inaccurate in detecting pancreatic cysts with advanced neoplasia: a clinicopathologic study of 225 patients with supporting molecular data. Gastrointest Endosc 2016;83:1107-1117.e2.
59. Singhi AD, McGrath K, Brand RE et al. Preoperative nextgeneration sequencing of pancreatic cyst fluid is highly accurate in cyst classification and detection of advanced neoplasia. Gut 2018;67:2131-2141.

60. Nikiforova MN, Khalid A, Fasanella KE, et al. Integration of KRAS testing in the diagnosis of pancreatic cystic lesions: a clinical experience of 618 pancreatic cysts. Mod Pathol Off $J U$ S Can Acad Pathol Inc 2013; 26: 1478-1487.

61. Jimenez RE, Warshaw AL, Z'graggen K, et al. Sequential accumulation of K-ras mutations and p53 overexpression in the progression of pancreatic mucinous cystic neoplasms to malignancy. Ann Surg 1999; 230: 501-509; discussion 509-511.

62. McCarty T, Paleti S, Rustagi T. Molecular analysis of EUSacquired pancreatic cyst fluid for K-ras and G-nasmutations for diagnosis of intraductal papillary mucinous neoplasia and mucinous cystic lesions: a systematic review and meta-analysis. Gastrointest Endosc. 2020. https://doi.org/10.1016/j.gie. 2020.12.014.

63. Shibata H, Ohike N, Norose T et al. Mucinous cystic neoplasms lined by abundant mucinous epithelium frequently involve KRAS mutations and malignant progression. Anticancer Res 2017;37:7063-7068.

64. Wu J, Jiao Y, Dal Molin M et al. Whole-exome sequencing of neoplastic cysts of the pancreas reveals recurrent mutations in components of ubiquitin-dependent pathways. Proc Natl Acad Sci U S A 2011;108:21188-21193.

65. Aparicio JR, Martínez J, Niveiro M et al. Direct intracystic biopsy and pancreatic cystoscopy through a 19-gauge needle EUS (with videos). Gastrointest Endosc 2010;72:1285-1288.

66. Crinò SF, Bernardoni L, Brozzi L et al. Association between macroscopically visible tissue samples and diagnostic accuracy of EUS-guided through-the-needle microforceps biopsy sampling of pancreatic cystic lesions. Gastrointest Endosc 2019;90:933-943.

67. Larghi A, Manfrin E, Fabbri C et al. Interobserver agreement among expert pathologists on through-the-needle microforceps biopsy samples for evaluation of pancreatic cystic lesions. Gastrointest Endosc 2019;90:784-792.e4.

68. Tacelli M, Celsa C, Magro B et al. Diagnostic performance of endoscopic ultrasound through-the-needle microforceps biopsy of pancreatic cystic lesions: Systematic review with meta-analysis. Dig Endosc Off J Jpn Gastroenterol Endosc Soc. 2020. https://doi.org/10.1111/den.13626.

69. Nakai Y, Isayama $\mathrm{H}$, Chang KJ et al. A pilot study of EUSguided through-the-needle forceps biopsy (with video). Gastrointest Endosc 2016;84:158-162.

70. Shakhatreh MH, Naini SR, Brijbassie AA et al. Use of a novel through-the-needle biopsy forceps in endoscopic ultrasound. Endosc Int Open 2016;4:E439-E442.

71. Kovacevic B, Karstensen JG, Havre RF et al. Initial experience with EUS-guided microbiopsy forceps in diagnosing pancreatic cystic lesions: A multicenter feasibility study (with video). Endosc Ultrasound 2018;7:383-388.

72. Barresi L, Crinò SF, Fabbri C et al. Endoscopic ultrasoundthrough-the-needle biopsy in pancreatic cystic lesions: a multicenter study. Dig Endosc Off J Jpn Gastroenterol Endosc Soc 2018;30:760-770.

73. Basar O, Yuksel O, Yang DJ et al. Feasibility and safety of microforceps biopsy in the diagnosis of pancreatic cysts. Gastrointest Endosc 2018;88:79-86.

74. Mittal C, Obuch JC, Hammad H et al. Technical feasibility, diagnostic yield, and safety of microforceps biopsies during EUS evaluation of pancreatic cystic lesions (with video). Gastrointest Endosc 2018;87:1263-1269.

75. Yang D, Samarasena JB, Jamil LH et al. Endoscopic ultrasound-guided through-the-needle microforceps biopsy in the 
evaluation of pancreatic cystic lesions: a multicenter study. Endosc Int Open 2018;6:E1423-E1430.

76. Yang D, Trindade AJ, Yachimski P et al. Histologic analysis of endoscopic ultrasound-guided through the needle microforceps biopsies accurately identifies mucinous pancreas cysts. Clin Gastroenterol Hepatol Off Clin Pract J Am Gastroenterol Assoc 2019;17:1587-1596.

77. Westerveld DR, Ponniah SA, Draganov PV et al. Diagnostic yield of EUS-guided through-the-needle microforceps biopsy versus EUS-FNA of pancreatic cystic lesions: a systematic review and meta-analysis. Endosc Int Open 2020;8:E656-E667.

78. Zhang ML, Arpin RN, Brugge WR et al. Moray micro forceps biopsy improves the diagnosis of specific pancreatic cysts. Cancer Cytopathol 2018;126:414-420.

79. Kovacevic B, Klausen P, Hasselby JP et al. A novel endoscopic ultrasound-guided through-the-needle microbiopsy procedure improves diagnosis of pancreatic cystic lesions. Endoscopy 2018;50:1105-1111.

80. Lakhtakia S, Ramchandani M, Galasso D et al. EUS-guided radiofrequency ablation for management of pancreatic insulinoma by using a novel needle electrode (with videos). Gastrointest Endosc 2016;83:234-239.

81. Kovacevic B, Klausen P, Rift CV, et al. Clinical impact of endoscopic ultrasound-guided through-the-needle microbiopsy in patients with pancreatic cysts. Endoscopy. Epub ahead of print 21 July 2020. DOI: https://doi.org/10.1055/a-1214-6043.

82. Durkin C, Krishna SG. Advanced diagnostics for pancreatic cysts: Confocal endomicroscopy and molecular analysis. World J Gastroenterol 2019;25:2734-2742.

83. Alvarez-Sánchez M-V, Napoléon B. New horizons in the endoscopic ultrasonography-based diagnosis of pancreatic cystic lesions. World J Gastroenterol 2018;24:2853-2866.

84. Facciorusso A, Buccino VR, Sacco R. Needle-based confocal laser endomicroscopy in pancreatic cysts: a meta-analysis. Eur J Gastroenterol Hepatol 2020;32:1084-1090.

85. Napoleon B, Krishna SG, Marco B et al. Confocal endomicroscopy for evaluation of pancreatic cystic lesions: a systematic review and international Delphi consensus report. Endosc Int Open 2020;8:E1566-E1581.

86. Konda VJA, Meining A, Jamil LH et al. A pilot study of in vivo identification of pancreatic cystic neoplasms with needle-based confocal laser endomicroscopy under endosonographic guidance. Endoscopy 2013;45:1006-1013.

87. Napoleon B, Lemaistre A-I, Pujol B et al. In vivo characterization of pancreatic cystic lesions by needle-based confocal laser endomicroscopy (nCLE): proposition of a comprehensive nCLE classification confirmed by an external retrospective evaluation. Surg Endosc 2016;30:2603-2612.

88. Napoléon B, Lemaistre A-I, Pujol B et al. A novel approach to the diagnosis of pancreatic serous cystadenoma: needle-based confocal laser endomicroscopy. Endoscopy 2015;47:26-32.

89. Napoleon B, Palazzo M, Lemaistre A-I et al. Needle-based confocal laser endomicroscopy of pancreatic cystic lesions: a prospective multicenter validation study in patients with definite diagnosis. Endoscopy 2019;51:825-835.

90. Krishna SG, Hart PA, DeWitt JM et al. EUS-guided confocal laser endomicroscopy: prediction of dysplasia in intraductal papillary mucinous neoplasms (with video). Gastrointest Endosc 2020;91:551-563.e5.

91. Machicado JD, Chao W-L, Carlyn DE et al. High performance in risk stratification of intraductal papillary mucinous neoplasms by confocal laser endomicroscopy image analysis with convolutional neural networks (with video). Gastrointest Endosc. 2021. https://doi.org/10.1016/j.gie.2020.12.054.
92. Karia K, Waxman I, Konda VJ et al. Needle-based confocal endomicroscopy for pancreatic cysts: the current agreement in interpretation. Gastrointest Endosc 2016;83:924-927.

93. Krishna SG, Swanson B, Hart PA et al. Validation of diagnostic characteristics of needle based confocal laser endomicroscopy in differentiation of pancreatic cystic lesions. Endosc Int Open 2016;4:E1124-E1135.

94. Krishna SG, Brugge WR, Dewitt JM et al. Needle-based confocal laser endomicroscopy for the diagnosis of pancreatic cystic lesions: an international external interobserver and intraobserver study (with videos). Gastrointest Endosc 2017;86:644654.e2.

95. Nakai Y, Iwashita T, Park DH et al. Diagnosis of pancreatic cysts: EUS-guided, through-the-needle confocal laser-induced endomicroscopy and cystoscopy trial: DETECT study. Gastrointest Endosc 2015;81:1204-1214.

96. Eiterman A, Lahooti A, Krishna SG. Endosonographic diagnosis of advanced neoplasia in intraductal papillary mucinous neoplasms. World J Gastroenterol 2020;26:3201-3212.

97. Cheesman AR, Zhu H, Liao X et al. Impact of EUS-guided microforceps biopsy sampling and needle-based confocal laser endomicroscopy on the diagnostic yield and clinical management of pancreatic cystic lesions. Gastrointest Endosc 2020;91:1095-1104.

98. Le Pen C, Palazzo L, Napoléon B. A health economic evaluation of needle-based confocal laser endomicroscopy for the diagnosis of pancreatic cysts. Endosc Int Open 2017;5:E987-E995.

99. Sahora K, Ferrone CR, Brugge WR et al. Effects of comorbidities on outcomes of patients with intraductal papillary mucinous neoplasms. Clin Gastroenterol Hepatol Off Clin Pract J Am Gastroenterol Assoc 2015;13:1816-1823.

100. Kwok K, Chang J, Duan L et al. Competing risks for mortality in patients with asymptomatic pancreatic cystic neoplasms: implications for clinical management. Am J Gastroenterol 2017;112:1330-1336.

101. Kawakubo K, Tada M, Isayama H et al. Risk for mortality from causes other than pancreatic cancer in patients with intraductal papillary mucinous neoplasm of the pancreas. Pancreas 2013;42:687-691.

102. Pergolini I, Sahora K, Ferrone CR et al. Long-term risk of pancreatic malignancy in patients with branch duct intraductal papillary mucinous neoplasm in a referral center. Gastroenterology 2017;153:1284-1294.e1.

103. Crippa S, Pezzilli R, Bissolati M et al. Active surveillance beyond 5 years is required for presumed branch-duct intraductal papillary mucinous neoplasms undergoing non-operative management. Am J Gastroenterol 2017;112:1153-1161.

104. Marchegiani G, Andrianello S, Pollini T et al. 'Trivial' cysts redefine the risk of cancer in presumed branch-duct intraductal papillary mucinous neoplasms of the pancreas: a potential target for follow-up discontinuation? Am J Gastroenterol 2019;114:1678-1684.

105. Moayyedi P, Weinberg DS, Schünemann $\mathrm{H}$ et al. Management of pancreatic cysts in an evidence-based world. Gastroenterology 2015; 148:692-695.

106. Canakis A, Maoz A, Tkacz JN et al. Factors affecting the rates of adherence to surveillance recommendations for incidental pancreatic cystic lesions in a large urban safety net hospital. BMJ Open Gastroenterol. 2020. https://doi.org/10.1136/bmjga st-2020-000430.

107. Schenck RJ, Miller FH, Keswani RN. The surveillance patterns of incidentally detected pancreatic cysts vary widely and infrequently adhere to guidelines. Pancreas 2019;48:883-887.

108. Lennon AM, Manos LL, Hruban RH et al. Role of a multidisciplinary clinic in the management of patients with pancreatic cysts: a single-center cohort study. Ann Surg Oncol 2014;21:3668-3674. 
109. Verma D, Kwok KK, Wu BU. Patient preferences for management of cystic neoplasms of the pancreas: a cross-sectional survey study. Pancreas 2017;46:352-357.

110. Choi JH, Lee SH, Choi YH et al. Clinical outcomes of endoscopic ultrasound-guided ethanol ablation for pancreatic cystic lesions compared with the natural course: a propensity score matching analysis. Ther Adv Gastroenterol 2018;11:175628481875992.

111. Moyer MT, Maranki JL, DeWitt JM. EUS-guided pancreatic cyst ablation: a clinical and technical review. Curr Gastroenterol Rep 2019;21:19.

112. Oh H-C, Brugge WR. EUS-guided pancreatic cyst ablation: a critical review (with video). Gastrointest Endosc 2013;77:526-533.

113. Teoh AY-B, Seo DW, Brugge W et al. Position statement on EUS-guided ablation of pancreatic cystic neoplasms from an international expert panel. Endosc Int Open. 2019;7:1064-1077.

114. Gan SI, Thompson CC, Lauwers GY et al. Ethanol lavage of pancreatic cystic lesions: initial pilot study. Gastrointest Endosc 2005;61:746-752.

115. DeWitt J, McGreevy K, Schmidt CM et al. EUS-guided ethanol versus saline solution lavage for pancreatic cysts: a randomized, double-blind study. Gastrointest Endosc 2009;70:710-723.

116. DiMaio CJ, DeWitt JM, Brugge WR. Ablation of pancreatic cystic lesions: the use of multiple endoscopic ultrasound-guided ethanol lavage sessions. Pancreas 2011;40:664-668.

117. Caillol F, Poincloux L, Bories E et al. Ethanol lavage of 14 mucinous cysts of the pancreas: a retrospective study in two tertiary centers. Endosc Ultrasound 2012;1:48-52.

118. Gómez V, Takahashi N, Levy MJ et al. EUS-guided ethanol lavage does not reliably ablate pancreatic cystic neoplasms (with video). Gastrointest Endosc 2016;83:914-920.

119. Park JK, Song BJ, Ryu JK et al. Clinical outcomes of endoscopic ultrasonography-guided pancreatic cyst ablation. Pancreas 2016;45:889-894.

120. Choi JH, Lee SH, Choi YH et al. Safety of endoscopic ultrasound-guided ethanol ablation for pancreatic cystic lesions: a single-center experience of 214 patients. Hepatobiliary Pancreat Dis Int HBPD INT 2019;18:562-568.

121. Choi J-H, Seo DW, Song TJ et al. Long-term outcomes after endoscopic ultrasound-guided ablation of pancreatic cysts. Endoscopy 2017;49:866-873.

122. Oh H-C, Seo DW, Song TJ et al. Endoscopic ultrasonographyguided ethanol lavage with paclitaxel injection treats patients with pancreatic cysts. Gastroenterology 2011;140:172-179.

123. Oh H-C, Seo DW, Kim SC et al. Septated cystic tumors of the pancreas: Is it possible to treat them by endoscopic ultrasonography-guided intervention? Scand J Gastroenterol 2009;44:242-247.

124. DeWitt JM, Al-Haddad M, Sherman S et al. Alterations in cyst fluid genetics following endoscopic ultrasound-guided pancreatic cyst ablation with ethanol and paclitaxel. Endoscopy 2014;46:457-464.

125. Oh H-C, Seo DW, Lee TY et al. New treatment for cystic tumors of the pancreas: EUS-guided ethanol lavage with paclitaxel injection. Gastrointest Endosc 2008;67:636-642.

126. Moyer MT, Dye CE, Sharzehi S et al. Is alcohol required for effective pancreatic cyst ablation? the prospective randomized CHARM trial pilot study. Endosc Int Open 2016;4:E603-E607.

127. Kim KH, McGreevy K, La Fortune K et al. Sonographic and cyst fluid cytologic changes after EUS-guided pancreatic cyst ablation. Gastrointest Endosc 2017;85:1233-1242.

128. Moyer MT, Sharzehi S, Mathew A et al. The safety and efficacy of an alcohol-free pancreatic cyst ablation protocol. Gastroenterology 2017;153:1295-1303.

129. Attila T, Adsay V, Faigel DO. The efficacy and safety of endoscopic ultrasound-guided ablation of pancreatic cysts with alcohol and paclitaxel: a systematic review. Eur J Gastroenterol Hepatol 2019;31:1-9.

130. CHARM II: Chemotherapy for ablation and resolution of mucinous pancreatic cysts - full text view - clinicaltrials.gov, https:// clinicaltrials.gov/ct2/show/NCT03085004

131. Allen BC, Chen MY, Childs DD et al. Imaging-guided radiofrequency ablation of cystic renal neoplasms. AJR Am J Roentgenol 2013;200:1365-1369.

132. Yoon HM, Baek JH, Lee JH et al. Combination therapy consisting of ethanol and radiofrequency ablation for predominantly cystic thyroid nodules. AJNR Am J Neuroradiol 2014;35:582-586.

133. Barthet M, Giovannini M, Lesavre N et al. Endoscopic ultrasound-guided radiofrequency ablation for pancreatic neuroendocrine tumors and pancreatic cystic neoplasms: a prospective multicenter study. Endoscopy 2019;51:836-842.

134. Pai M, Habib N, Senturk H et al. Endoscopic ultrasound guided radiofrequency ablation, for pancreatic cystic neoplasms and neuroendocrine tumors. World J Gastrointest Surg 2015;7:52-59.

135. Slovak R, Ludwig JM, Gettinger SN et al. Immuno-thermal ablations - boosting the anticancer immune response. J Immunother Cancer. 2017. https://doi.org/10.1186/s40425-017-0284-8.

136. Oh D, Ko SW, Seo D-W et al. Endoscopic ultrasound-guided radiofrequency ablation of pancreatic microcystic serous cystic neoplasms: a retrospective study. Endoscopy. 2020. https://doi. org/10.1055/a-1250-7786.

Publisher's Note Springer Nature remains neutral with regard to jurisdictional claims in published maps and institutional affiliations. 